\title{
Sistemas de derecho, fuentes y pluralismo jurídico
}

\author{
Kamachikuy kayniyukuna, yalamuninkuna achkakunap \\ kamachikuy
}

Okantagetanaka, netsëgotagetiro ora timagatsipagekë

\author{
Okantakoyetari sabikakayeri Kametsa, onashiyeta \\ okantakoyetari
}

Recibido: 10 Agosto 2019 Corregido: 22 Diciembre 2019 Aprobado: 12 Marzo 2020

Frank Luis Mila Maldonado, Nacionalidad: Española

Filiación: Universidad de Otavalo,

Correo:fmila@uotavalo.edu.ec; ORCID: https://orcid.org/oooo-0003-4363-5092

Karla Ayerim Yánez Yánez, Nacionalidad: Venezolana

Filiación: Universidad de Otavalo

Correo: kyanez2253@gmail.com; ORCID: https://orcid.org/oooo-0o03-0441-9354

\section{Resumen}

En Ecuador han coexistido diversos grupos sociales, como lo son los pueblos indígenas, campesinos y afrodescendientes, los cuales se han caracterizado por manejar un derecho propio, alejado del centralismo estatal. En materia de pluralismo jurídico, la costumbre juega un papel determinante, aunque el código civil ecuatoriano establece que solo debe aplicarse cuando la ley lo indica, debe ser visualizada como una manifestación de prácticas reiteradas en el tiempo, traduciéndose en una fuente primaria del derecho por parte de los grupos que forman parte del pluralismo jurídico, destacándose la justicia indígena como la más relevante representación de la coexistencia de ordenamientos jurídicos.

\section{Palabras clave:}

Fuentes del Derecho, Sistemas de Derecho, Sistema Continental, Pluralismo Jurídico, Justicia Indígena.

\section{Lisichiku limaykuna:}

kamachiku yalamuyninkuna, kamachikup kayninkuna, kilkasha kamachikuykuna, achkakunap kamachikuykuna, malkanunakunap kamachikuy.

\section{Nibarintsipage Katingaro:}

okantagetanaka, nibarintsipage, kara okatingatagetiri, kara yapatoita, matsgenga

\section{Ñantsipe ayoyeteri:}

Opoñari kisakotantsi, okantakoyetari kisakoyetantsi, okantakoyetari maroniki nampitsipe, onashiyetari kisakoyetantsi, okantari abetsikayetiro pomerentsitantsi. 


\title{
Systems of Law, Sources and Legal Pluralism
}

\begin{abstract}
In Ecuador, various social groups have coexisted, such as indigenous, peasant and Afro-descendant peoples, which have been characterized by managing their own right, far from state centralism. In the matter of legal pluralism, custom plays a decisive role, although Ecuadorian civil code states that it should only be applied when the law indicates it, it should be visualized as a manifestation of repeated practices over time, translating into a primary source of law by of the groups that are part of legal pluralism, highlighting indigenous justice as the most relevant representation of the coexistence of legal systems.
\end{abstract}

\section{Sistemas de direito, fontes e pluralismo jurídico}

\section{Resumo}

No Equador, vários grupos sociais coexistiram tais como os povos indígenas, camponeses e afrodescendentes, caracterizados por administrar seus próprios direitos, longe do centralismo estatal. $\mathrm{Na}$ questão do pluralismo jurídico, o costume desempenha um papel decisivo, embora o código civil equatoriano estabelece que só deve ser aplicado quando a lei o indicar, o que deve ser visualizado como uma manifestação de práticas repetidas ao longo do tempo, traduzindo-se em uma fonte primária de direito por parte dos grupos que fazem parte do pluralismo jurídico, destacando-se a justiça indígena como a representação mais relevante da coexistência de ordenamentos jurídicos.

\section{Keywords}

Sources of Law, Systems

of Law, Written Law Legal

Pluralism, Indigenous

Justice.

\author{
Palavras-chave: \\ Fontes de direito, sistemas \\ de direito, sistema \\ continental, pluralismo \\ jurídico, justiça indígena.
}

\section{Datos de los autores}

Frank Luis Mila Maldonado: Investigador y docente de derecho y educación. Doctor en Educación por la Universidad Santa María y Doctorando en Derecho por la Universidad Católica Andrés Bello.

Karla Ayerim Yánez Yánez: Investigadora y docente de derecho. Abogada. Maestrante en Derecho Constitucional por la Universidad de Otavalo. 


\section{Introducción}

El pluralismo jurídico es un fenómeno que incide fuertemente en los sistemas de derecho, ya que el mismo presupone la coexistencia de dos o más sistemas, lo que puede generar problemas jurídicos e instrumentales en cuanto a la aplicación en cada caso concreto.

En el caso del Ecuador, la máxima representación del pluralismo se materializa mediante los derechos de los pueblos y comunidades indígenas, los cuales han sido reconocidos constitucionalmente en la mayoría de los países latinoamericanos, e incluso a nivel internacional consagrándose en instrumentos internacionales como el Convenio 169 de la Organización Internacional del Trabajo “OIT” (1989), así como la Declaración de las Naciones Unidas sobre los derechos de los pueblos indígenas (2007).

Es por ello, que dentro de los sistemas de derecho existentes, como lo son el sistema continental o de derecho escrito conocido como Written Law y el sistema anglosajón o también llamado Common Law, el primero de ellos basado en la ley como fuente directa y el segundo en la jurisprudencia, adicionalmente a las fuentes directas o materiales, existen otras fuentes como lo son las históricas y las fuentes primarias, dentro de las cuales se encuentran la analogía, los principios generales del derecho, la doctrina y la costumbre, esta última íntimamente relacionada con el pluralismo jurídico, en virtud que la justicia indígena, se considera una práctica milenaria de derecho consuetudinario, basada en la costumbre, convirtiéndose esta entonces en una fuente primaria de derecho.

\section{Generalidades sobre los Sistemas de Derecho}

Generalmente el derecho contemporáneo se ha estructurado sobre la base de sistemas jurídicos, siendo definidos los sistemas jurídicos (o de derecho), según García (1989), como el conjunto de normas jurídicas que están en vigor en determinado lugar y época, y que el Estado estableció o creó con la finalidad de regular la conducta o el comportamiento humano. (p. 189).

En tal sentido, es importante destacar que los sistemas jurídicos más característicos o básicos del derecho contemporáneo son los denominados a) continental o de derecho escrito (Written Law) y b) anglosajón o de derecho consuetudinario (Common Law). A pesar que se adicionan diversos sistemas, entre los cuales destacan: sistemas religiosos, sistemas socialistas, sistemas asiáticos, sistemas africanos, sistema supranacional de la Unión Europea, entre otros, tomamos en consideración los dos sistemas más notorios y básicos para estructurar el manejo del derecho según sus fuentes.

Así, cada uno de los principales sistemas (Written y Common Law) presenta características particulares que condicionan el tratamiento del Derecho en un determinado Estado.

Ahora bien, sostiene Martínez (2011), que:

"La expresión “Sistemas de derecho" se debe al Profesor francés René David, quien la elaboró con el fin de comparar los derechos entre distintos Estados. Consciente de que el número de Derechos existentes en el mundo era infinito, observó sin embargo este Profesor, que muchos de ellos podían ser reagrupados de acuerdo con criterios tales como la técnica legislativa empleada, la manera de clasificar las reglas y los modos de razonamiento empleados por los intérpretes". (p. 26) 
Así tenemos que es una realidad que los Estados se manejan conforme a sistemas jurídicos distintos, ya que no existen dos Estados que tengan identidad plena en sus sistemas, sin embargo, tal como se plasmó ut supra, existen aspectos en común que rigen para los sistemas, que permite reducirlos en dos grandes bloques (continental o anglosajón), atendiendo principalmente a elementos en común, que en este caso son las denominadas fuentes del Derecho. Estos sistemas se caracterizan según el valor que otorgan a cada fuente del derecho, entendiéndose el término fuente de derecho a todo aquello que contribuye a crear el sistema de normas, y cada sistema se caracteriza por poseer una fuente directa por excelencia, siendo la ley para el sistema continental y la jurisprudencia para el anglosajón.

En tal sentido, el sistema a) continental o de derecho escrito (Written Law), está basado en la aplicación como fuente directa de la Ley, lo cual significa que la fuente que produce Derecho es la Ley, siendo la institución vinculante que se aplicará en los diversos casos concretos que ingresen a la esfera del derecho.

En el mismo orden de ideas, el sistema de derecho escrito (Written Law), se define así:

Se llama sistema de tradición continental o civilista, o, simplemente, "Civil Law", al "sistema jurídico que, heredero del derecho romano a través de la Codificación de Justiniano, se consolida en la gran codificación del siglo XIX. Además, apunta que este sistema rige en la Europa Continental, Latinoamérica y varios países asiáticos" (Gottheil, 1960, p.17). En consecuencia, el sistema de derecho continental se caracteriza por ser un sistema de derecho escrito que reposa en códigos... y cuyos principios fundamentales son similares debido a que provienen de las instituciones de Derecho Romano. (Martínez, 2011, p. 37).

\section{Con respecto al sistema Continental europeo, se define según Mila (2012) así:}

Es un sistema cerrado en cuanto a la producción de normas jurídicas, tenemos que, de acuerdo con el principio de plenitud hermética del ordenamiento jurídico, el Derecho prevé soluciones para todos los casos que se puedan presentar a la consideración del Juez, así debe considerarse en primer lugar a la Ley, en caso de ella presentar algunos vacíos o lagunas deberá acudirse a las fuentes subsidiarias o instrumentos de integración: analogía y principios generales del Derecho. (p. 272)

Como se evidencia, en el sistema de derecho continental, la fuente directa es la Ley y en caso de presentarse vacíos o lagunas, se acude a fuentes supletorias o subsidiarias que llenan los mismos, en tal sentido, fuentes como la jurisprudencia, la costumbre y la doctrina, quedan relegadas a fuentes interpretativas, lo que se traduce en la aplicación de hermenéutica (interpretación) empero, no integración (suplir vacíos legislativos) del derecho con estas últimas.

En resumen, las fuentes en el sistema written law se basan principalmente o circundan en torno a la ley, que se traduce en que la fuente vinculante a aplicar en un caso concreto, es la ley, que puede ir acompañada de fuentes que suplen sus vacíos, a saber: la analogía y los principios generales del derecho. Asimismo, existen otras fuentes que son de carácter interpretativas, que coadyuvan a determinar el alcance de la ley, a saber: jurisprudencia y la doctrina jurídica. Por último, surge un tertium genus, que es la costumbre, fuente que en algunos ordenamientos de derecho continental se aplica siempre que la ley lo permita (costumbre praeter legem), la cual, de igual manera reviste una importancia cardinal, en virtud que abre las puertas para hablar de sistemas pluralistas (caso de costumbres de pueblos y tradiciones indígenas), la cual será explicada en el capítulo correspondiente del presente artículo. 
Por otra parte, con respecto al sistema b) anglosajón o de derecho consuetudinario (Common Law), este radica en que la fuente directa o principal ya no será la ley sino la costumbre reflejada en la jurisprudencia, es decir, la fuente directa es la jurisprudencia (precedentes).

En tal sentido, el sistema Common Law nace en Inglaterra, específicamente en la Edad Media, gracias a las diversas decisiones emanadas de los Tribunales Reales y las cuales se sustentaban en la costumbre local. Este sistema es aplicado en la actualidad en países como Estados Unidos, Nueva Zelanda, Canadá, Australia, Irlanda, Inglaterra, entre otros.

Dicho lo anterior, cabe advertir que el sistema ha sufrido sus variantes, no siendo unísono históricamente, por lo cual atravesó una evolución, en la cual se llegó a dividir el Common Law en el sistema propiamente y en la equity (normas creadas mediante la jurisdicción del denominado canciller, con la finalidad de complementar y revisar el common law que consideraba deficiente, con la finalidad de completar el sistema). En tal sentido, siguiendo a Sirvent (2015), tal división atendía (y atiende, en los países en los cuales aún opera) a lo siguiente:

Las materias que conoce el Common Law son el derecho penal, contratos, responsabilidad civil (tort). La equity conoce de propiedad real (trust), sociedades comerciales, quiebras, interpretación de los testamentos y liquidación de sucesiones (p.72-73). Sin embargo, sostiene que en la praxis la equity abarca ciertas materias nuevas y se ha apoderado de nuevas materias, tendiendo a convertirse en el conjunto de materias que se estima conveniente hacer juzgar conforme a un procedimiento escrito, en tanto, las materias del common law, serán juzgadas de manera oral. (p.72-73)

Ahora bien, a pesar de lo indicado anteriormente lo más relevante en este sistema es el sistema de fuentes, el cual está constituido por el precedente (jurisprudencia o decisión previa -stare decisis-), la legislación, la costumbre, la razón y la doctrina.

Se denota que la fuente principal es el precedente y este, según Legarre y Rivera (2006), se traduce en denominarlo stare decisis, que consiste en:

Stare decisis es el nombre abreviado de la doctrina que constituye la esencia del sistema jurídico imperante en los países anglosajones. Este sistema, como es sabido, se llama common law. El nombre completo de la doctrina es stare decisis et quieta non movere, que significa, en traducción flexible, "estar a lo decidido y no perturbar lo ya establecido, lo que está quieto". La idea general que subyace a la doctrina es la del respeto por las decisiones precedentes -o, simplemente, los "precedentes"-, es decir, decisiones tomadas previamente por otros tribunales que resolvieron un problema semejante. (p.109-110)

Dicho lo anterior, se puede resumir en palabras de Legarre y Rivera (2006), que la diferencia entre el derecho anglosajón y el derecho continental radica en:

La principal diferencia entre el derecho anglosajón y el derecho continental radica en la institución del precedente judicial obligatorio como regla de derecho. Los jueces en el derecho anglosajón están obligados a resolver los casos que se les presenten ateniéndose a las soluciones de sentencias dictadas anteriormente en casos similares, tanto por sus superiores jerárquicos (stare decisis vertical), como por jueces de la misma jurisdicción incluidos ellos mismos (stare decisis horizontal). (p.109). 


\section{Fuentes del Derecho}

Las fuentes del derecho es un término que actualmente ha sido superado, es decir, pocos autores discuten que el término sea empleado para referirnos a aquello que genera derecho (fundamento u origen de algo, en este caso del derecho).

Sostiene Mila (2012) que:

La doctrina admite que el término "fuentes", acompañado del vocablo Derecho, resulta metafórico, lo que por sí solo revela la dificultad para encontrarle un significado conceptual unívoco, razón por la cual ha sido seriamente cuestionado por la doctrina (p. 268). Incluso, la Rae, en unas de sus definiciones sostiene que: Fuente: Del lat. fons, fontis. (...) 7. f. Principio, fundamento u origen de algo.

Ahora bien, la doctrina insiste en que los mayores aportes a esta institución se deben a Savigny, quien desarrolla su planteamiento sobre la base de que el Derecho se origina en el espíritu del pueblo. Las fuentes, no son otra cosa que su manifestación (Mila, 2012, p. 272).

Posteriormente, otros autores han debatido sobre la aceptación y el alcance del término, existiendo un grupo de detractores (Kelsen, Santiromano -prefiriendo hablar de orden u ordenamiento jurídico-) y partidarios (Del Vecchio, Legaz y Lacambra, entre otros, quienes varían sobre el alcance, empero coinciden con el término), lo cierto es que la mayoría de autores concluyen en mayor o en menor medida que el derecho es generado por una fuente, Ilámese ordenamiento jurídico, orden jurídico, norma jurídica, ley, costumbre o de cualquier otra manera, aun cuando son términos que no son idénticos, la connotación que se persigue con el término fuentes es que se busca una denominación univoca para referirse a aquello que genera el Derecho.

Adicionalmente, el tema de las fuentes guarda especial relación con el pluralismo jurídico, precisamente este nace por la pluralidad de fuentes del Derecho, lo cual implica que ya no en todos los Estados se habla de un sistema con única fuente, sino de pluralidad de sistemas que pueden coexistir en un mismo espacio político-territorial empero, con sustentos o fuentes distintas.

\section{Fuentes del Derecho en Ecuador}

Ahora bien, las fuentes del Derecho atienden a diversas clasificaciones según el sistema que maneje cada Estado, no obstante, la enumeración clásica de las mismas, son: 1.- La ley, 2.- La analogía, 3.- Los Principios Generales del Derecho, 4.- La Costumbre, 5.- La jurisprudencia y 6.- La Doctrina jurídica.

Adicional a la anterior clasificación, la doctrina suele escindir entre fuentes 1.- Históricas (aquellas que tienen valor para el estudio del pasado del Derecho, tratándose de cualquier documento con contenido jurídico de relevancia -documentos, papiros, folios, tablas, entre otros-), 2.- Reales o Materiales (se trata de aquellos factores económicos, sociales, políticos, religiosos de otra índole que determinan el contenido de las fuentes formales) y 3.- Formales (las que generan el derecho propiamente dicho, es decir, son aquellas vinculantes para el juez de manera primaria en relación a la resolución de cada caso concreto). 
Además, suele establecerse otra división de las fuentes, que hace referencia a fuentes directas (la ley -sistemas continentales- o la jurisprudencia -sistema anglosajón-) e indirectas (no contienen en sí las normas jurídicas, empero, ayudan a suplir vacíos normativos -analogía, principios del derecho- o coadyuvan a interpretar -jurisprudencia y la doctrina-).

Ahora bien, en Ecuador se estatuye la siguiente clasificación de las fuentes del Derecho:

La Ley: Ahora bien, en el presente texto no se pretende realizar un estudio exhaustivo de cada fuente que conforma el sistema de derecho ecuatoriano, únicamente se procura realizar un esbozo general de cuáles son las fuentes que rigen, así como el valor que tiene cada. En tal sentido, considera Salgado (2014) que:

En los sistemas jurídicos modernos de Derecho escrito, que son la mayoría, la legislación es la primera de las fuentes formales. Hay que comenzar señalando que es preferible utilizar la palabra "legislación en lugar de "” ley" por su contenido amplio, globalizante, y además porque, como dice García Máynez, la ley es producto de la legislación y no debe ser considera propiamente, como fuente (p. 117)

Con respecto a esta fuente, debemos indicar que se trata de la fuente directa por excelencia, esto en relación al sistema monista, es decir, el sistema jurídico estatal se erige sobre la ley, no obstante, atendiendo al sistema pluralista que opera en Ecuador ello no es así, ya que existe otra fuente directa que se basa en las costumbres y practicas ancestrales, consideradas fuente directa. No obstante, la Ley (expresamos o designamos con el nomen de ley al orden jurídico, incluso a la Constitución) será tomada en consideración incluso en relación al sistema plural, en virtud que en la aplicación de estas prácticas o costumbres propias de comunidades en las cuales opera el pluralismo, se deben observar derechos constitucionales o aspectos relativos a los derechos humanos.

Igualmente, sea legislación o ley, de igual manera se presentan dicotomías con respecto al término ley y otras denominaciones, tales como la de norma jurídica, por ello en el presente texto entendemos que la acepción ley presenta particularidades propias que lo diferencian de legislación, o norma jurídica, siendo términos con distintos significados, empero se usarán en la presente obra como sinónimos con un fin meramente didáctico.

Por otra parte, es importante destacar que en la legislación (ley o norma jurídica), se atiende a un orden jurídico que atiende a jerarquías, encontrándose en primer término una norma programática que es la Constitución, que a grandes rasgos consagra aspectos dogmáticos y orgánicos fundamentales para la conformación de un Estado. Precisamente es la Constitución (2008) la que hace referencia al procedimiento de elaboración de leyes, así como a qué ente corresponde tal actividad legislativa, a saber:

Sección tercera Procedimiento legislativo

Art. 132.- La Asamblea Nacional aprobará como leyes las normas generales de interés común. Las atribuciones de la Asamblea Nacional que no requieran de la expedición de una ley se ejercerán a través de acuerdos o resoluciones. Se requerirá de ley en los siguientes casos: (...) (Resaltado nuestro)

Adicionalmente, el artículo 133 de la Constitución in commento, estatuye la gradación de normas en el siguiente tenor: 
Art. 133.- Las leyes serán orgánicas y ordinarias. (...). (Resaltado nuestro)

Por otra parte, el Código Civil Ecuatoriano (2005), consagra que:

Artículo 1.-

La ley es una declaración de la voluntad soberana que, manifestada en la forma prescrita por la Constitución, manda, prohíbe o permite.

Son leyes las normas generalmente obligatorias de interés común

Cabe destacar que en los sistemas de derecho escrito la ley es la fuente directa por antonomasia, siendo esta fuente formal, escrita, general y abstracta, que debe emanar de un órgano competente del Estado y obliga a todos sus habitantes.

La Analogía: Anteriormente se indicó que la ley es la fuente directa en los sistemas de derecho escrito, en tal sentido, la ley en ocasiones no regula la totalidad de las conductas que pueden requerir la intervención del derecho, es decir, existen situaciones fácticas en las cuales no se contemplan todos los supuestos o consecuencias jurídicas.

Por ello, en derecho se hace referencia al principio de plenitud hermética del Derecho, que significa que el derecho siempre tiene soluciones ante cualquier caso planteado (hablamos de caso en vez del término "conflicto", en virtud que esta corriente alemana ha sido superada, incluso desde el punto de vista del Derecho procesal, ya que no necesariamente el derecho interviene ante conflictos, sino ante intereses o relaciones), por ello, un juez no puede alegar la falta (u oscuridad) en la normativa como justificación para no resolver un caso planteado, siempre están obligados a decidir, en principio conforme a la fuente directa, o en su defecto (en caso de oscuridad o laguna) decidir conforme a fuentes supletorias, que en este caso son la analogía o los principios generales del derecho.

Lo anterior encuentra fundamento en el artículo 18 del Código Civil Ecuatoriano (2005) que dispone:

\section{Código Civil.}

Artículo.18.- Los jueces no pueden suspender ni denegar la administración de justicia por oscuridad o falta de ley. En tales casos juzgarán atendiendo a las reglas siguientes:

7a. A falta de ley, se aplicarán las que existan sobre casos análogos;

y no habiéndolas, se ocurrirá a los principios del derecho universal.

Visto lo anterior, es evidente que ante cualquier vacío se recurre a la analogía o en su defecto a los principios generales del derecho. En tal sentido, la analogía significa o se refiere a la aplicación de una norma similar o análoga para resolver el caso concreto, haciendo la salvedad que en materia penal existen ciertas reservas para aplicar la analogía (a menos que se trate de la denominada in bonam -buena- parte).

Los principios generales del derecho: Con relación a los principios generales del derecho, valen las mismas observaciones realizadas con respecto a la analogía, se trata de una fuente indirecta que tiene un carácter supletorio, que al no existir norma análoga para dar respuesta a un caso concreto se acude a los principios generales del derecho. Aplica de igual manera el contenido del artículo 18 del Código Civil Ecuatoriano que dispone: Código Civil. Artículo. 18.- Los jueces no pueden suspender ni denegar la administración de justicia por oscuridad o falta de ley. En tales casos juzgarán atendiendo a las reglas siguientes: (...) 7a. A 
falta de ley, se aplicarán las que existan sobre casos análogos; y no habiéndolas, se ocurrirá a los principios del derecho universal.

Es importante destacar que todas las ramas del derecho tienen principios, principios que en ocasiones sirven de contención o para proteger al individuo del poder del Estado y para reafirmar ciertos valores o aspectos que van intrínsecos con el concepto de dignidad humana (en el entendido que el ius naturalismo se ha impuesto en los últimos tiempos, superando muchos aspectos del positivismo clásico).

Igualmente, en relación al tema de los principios, vale acotar que actualmente sigue siendo un tema medular de discusión por parte de la Teoría del Derecho, existiendo una gran cantidad de obras que atizan la discusión, entre las cuales destacan a los teóricos Ronald Dworkin, Herbert Hart, Robert Alexy, incluyendo a los maestros españoles Miguel Atienza y Juan Ruiz Manero (incluso le endilgan otras denominación es tales como mandatos de optimización), entre otros, debatiendo más allá de su naturaleza su valor frente a las normas, por ello incluso se hace referencia a reglas y principios.

Al respecto, apunta Monroy (2015), que:

La revalorización de los principios que se presenta hoy ha sido puesta de presente en la polémica entre el profesor Ronald Dworkin que ha enarbolado la bandera de los principios y criticado la concepción de su antecesor en la cátedra de Oxford H. L.A. Hart, según la cual el derecho es un sistema de reglas. (...) (...) En todo caso se debe reconocer la importancia creciente 4 de una lectura principalista en todos los ámbitos del derecho. Después de la segunda guerra mundial se observa cada vez más frecuente a los "principios generales del derecho" y al reconocimiento de que los principios se diferencian de reglas o normas jurídicas (...). (p. 287).

Dicho lo anterior, lo que es indiscutible es que todo el ordenamiento jurídico se sustenta en principios, los cuales, a pesar de tener diversas acepciones y diversas funciones, tales como servir de protección de derechos.

La costumbre: Esta fuente del derecho es una de las más relevantes en atención de la presente obra, ya que a pesar que en el entendido que una de las máximas representaciones del pluralismo jurídico se refleja en la justicia indígena y esta a su vez se erige sobre la base de prácticas ancestrales, estas se asemejan o encuentran la mayor similitud en la costumbre como fuente del Derecho.

En tal sentido, pasamos a realizar algunas consideraciones relativas a la costumbre en aras de precisar si ésta realmente se corresponde con las prácticas indígenas, lo cual se traduce en la cabida del derecho consuetudinario como fuente de la justicia indígena, abriendo así la costumbre las puertas al pluralismo, o en su defecto, no pueden equipararse.

Desde un punto de vista sociológico:

La costumbre, sociológicamente es una manera de comportarse los hombres, un comportamiento que reviste caracteres de continuidad y permanencia. En consecuencia, si no hay permanencia y continuidad no hay costumbre, sino simplemente un acto aislado. La costumbre en sentido sociológico abarca desde el hábito propiamente dicho, hasta la costumbre racional. (Mila, 2012, p. 303) 
Del hábito a la costumbre jurídica se traduce en lo siguiente:

En tal sentido, se representa por hábitos (tendencia de repetir actos humanos), que abarcan: Automatismo Psicológico (realización de actos inconscientes), Imitación (tendencia de conformar actos sobre la base de los ajenos) y experiencia (representa la base racional de la costumbre, siendo el hombre capaz de realizar actos sobre la base de los ajenos considerándolos buenos o necesarios). (Mila, 2012, p. 303)

Es decir, del hábito se llega a la costumbre, los comportamientos contenidos en los hábitos se refuerzan con su repetición y cada vez se hace mayor, al reforzarse cada vez son más necesarios y adquieren fijeza, en consecuencia, robustecen su obligatoriedad y se van transformando en auténticas figuras del comportamiento social, haciéndose cada vez más obligatoria para los cohabitantes del grupo social. Así pues, el hábito será costumbre jurídica, cuando existe la convicción que la infracción de la costumbre, engendra una sanción jurídica por medio de la intervención de un órgano del Estado. En ese sentido, la costumbre suele ser un producto social. (Mila, 2012, p. 304)

Visto lo anterior, se comienzan a asomar los aspectos que caracterizan la costumbre, los cuales se resumen en un elemento 1) Material -objetivo- Inveterata Consuetudo (que consiste en los actos repetidos), en tal sentido este elemento debe contener adicionalmente debe ser: a) General (observada por todos los integrantes de una determinada comunidad), b) Constante (que se maneje cierta periodicidad), c) uniforme (consolidada, cada vez más fortalecida) y d) Notoria (Que se realice públicamente no en secreto).

Por otra parte, ubicamos el elemento 2) subjetivo -psicológico- Opinio iuiris necessitatis (que consiste en la creencia o convencimiento que el acto repetido es obligatorio desde un punto de vista jurídico).

Adicional a los elementos tradicionales antes mencionados, hay que mencionar que existen diversas teorías que buscan explicar el fundamento de la costumbre, tales como la teoría de la concesión (entendida como una concesión por parte del Estado), la teoría del uso (dada por el uso reiterado de la misma que hace que la fundamente), la teoría de la convicción (auspiciada por autores como Savigny que consideran que es una conciencia o espíritu del pueblo expresada como conducta o práctica social) y por último, la teoría de la voluntad social (manifestada mediante una voluntad colectiva, por tanto, se trata de una ley en el sentido que la sociedad considera que es imperativa).

Desde una óptica general observamos que la costumbre jurídica es una elaboración no pensada precisamente en la óptica de comunidades indígenas, sin embargo, la misma reúne unos requisitos o elementos que perfectamente hacen posible que pueda ser extendida o aplicada a la temática del pluralismo jurídico en su vertiente de la justicia indígena, en virtud que precisamente el sustento de tal sistema se erige sobre la base de costumbres, así estas reciban diversas denominaciones tales como prácticas ancestrales o tradiciones, finalmente se traducen en costumbres. Por ello la justicia indígena al ser definida se le incluye el aspecto atinente a la costumbre.

Por otra parte, vale destacar que legislativamente la costumbre en el Derecho ecuatoriano no constituye fuente del derecho, excepto en aquellos casos en los que la ley remita expresamente a su aplicación. Lo anterior encuentra cobijo en el artículo 2 del Código Civil que dispone: 


\section{Código Civil.}

Artículo. 2.- La costumbre no constituye derecho sino en los casos en que la ley se remite a ella.

Más allá de su prohibición desde la óptica del derecho civil (extensiva al derecho penal, esta vez por la consagración del principio de legalidad que prohíbe su uso en materia penal, más allá que existan excepciones in bonam parte) la Constitución hace referencia a su aceptación por parte de los pueblos y nacionalidades indígenas existentes en el país, en el entendido que se equipara este sistema sobre la base de derecho consuetudinario.

\section{Constitución de la República del Ecuador.}

Sección segunda Justicia indígena

Art. 171.- Las autoridades de las comunidades, pueblos y nacionalidades indígenas ejercerán funciones jurisdiccionales, con base en sus tradiciones ancestrales y su derecho propio, dentro de su ámbito territorial, con garantía de participación y decisión de las mujeres. Las autoridades aplicarán normas y procedimientos propios para la solución de sus conflictos internos, y que no sean contrarios a la Constitución y a los derechos humanos reconocidos en instrumentos internacionales. El Estado garantizará que las decisiones de la jurisdicción indígena sean respetadas por las instituciones y autoridades públicas. Dichas decisiones estarán sujetas al control de constitucionalidad. La ley establecerá los mecanismos de coordinación y cooperación entre la jurisdicción indígena y la jurisdicción ordinaria.

Visto el artículo anterior y atendiendo al más alto grado del orden jurídico, es evidente que se reconoce constitucionalmente la aplicación de la costumbre indígena en el derecho ecuatoriano.

La Jurisprudencia: La jurisprudencia es una de las fuentes que ha adquirido mayor relevancia en los últimos tiempos, en virtud que, por una parte, sigue siendo protagonista en lo que respecta al sistema anglosajón, por ser fuente directa, así, apunta Olaso (2007), que:

En el sistema anglosajón, la Jurisprudencia va a ser considerada un "precedente", recopilada generalmente en colecciones, que no será utilizada como una ley escrita, pero tampoco será derogada nunca. Podrá pasar mucho tiempo olvidada; pero si, aún algunos siglos después, un abogado encuentra en ella "su precedente, la vieja sentencia saldrá de su rincón y brillará su vigor y fuerza de "fuente directa de derecho". (p. 175)

Sostenido lo anterior, es importante indicar que en lo que atañe a algunos países en los cuales se maneja el sistema continental, como ocurre en el caso del Derecho venezolano y el ecuatoriano, ha venido tomado mayor fuerza, a pesar, que en principio, según el artículo 3 del Código Civil, las sentencias judiciales no tienen fuerza obligatoria sino respecto de las causase en que se pronunciaren, sin embargo, al revisar la Constitución de la República del Ecuador, se ubican los siguientes artículos relacionados con esta fuente:

Art. 11.- El ejercicio de los derechos se regirá por los siguientes principios:

8. El contenido de los derechos se desarrollará de manera progresiva a través de las normas, la jurisprudencia y las políticas públicas. El Estado generará y garantizará las condiciones necesarias para su pleno reconocimiento y ejercicio.

Capítulo tercero Garantías jurisdiccionales

Art. 86.- Las garantías jurisdiccionales se regirán, en general, por las siguientes disposiciones: 
5. Todas las sentencias ejecutoriadas serán remitidas a la Corte Constitucional, para el desarrollo de su jurisprudencia.

Art. 184.-serán funciones de la Corte Nacional de Justicia, además de las determinadas en la ley, las siguientes:

2. Desarrollar el sistema de precedentes jurisprudenciales fundamentado en los fallos de triple reiteración.

De los artículos precedentes se desprende que el constituyente le otorga cierta relevancia al desarrollo jurisprudencial, por una parte, inscribiendo a esta fuente como uno de los instrumentos encargados de desarrollar progresivamente los derechos, asimismo, se ordena que todas las sentencias ejecutoriadas sean remitidas a la Corte Constitucional, en aras de desarrollar su jurisprudencia y por otra parte, incluye como función de la Corte Nacional de Justicia, desarrollar el sistema de precedentes jurisprudenciales.

Adicionalmente, la jurisprudencia adquiere un mayor valor en dos casos específicos, consagrados en los siguientes artículos:

Art. 185.- Las sentencias emitidas por las salas especializadas de la Corte Nacional de Justicia que reiteren por tres ocasiones la misma opinión sobre un mismo punto, obligarán a remitir el fallo al pleno de la Corte a fin de que esta delibere y decida en el plazo de hasta sesenta días sobre su conformidad. Si en dicho plazo no se pronuncia, o si ratifica el criterio, esta opinión constituirá jurisprudencia obligatoria.

La jueza o juez ponente para cada sentencia será designado mediante sorteo y deberá observar la jurisprudencia obligatoria establecida de manera precedente. Para cambiar el criterio jurisprudencial obligatorio la jueza o juez ponente se sustentará en razones jurídicas motivadas que justifiquen el cambio, y su fallo deberá ser aprobado de forma unánime por la sala.

Art. 436.- La Corte Constitucional ejercerá, además de las que le confiera la ley, las siguientes atribuciones:

6. Expedir sentencias que constituyan jurisprudencia vinculante respecto de las acciones de protección, cumplimiento, hábeas corpus, hábeas data, acceso a la información pública y demás procesos constitucionales, así como los casos seleccionados por la Corte para su revisión.

Los anteriores artículos reflejan los dos supuestos in commento, 1.- Sentencias de triple reiteración, emanadas de la Corte Nacional de Justicia y 2.- Sentencias de la Corte Constitucional, en acciones de protección, cumplimiento, hábeas corpus, hábeas data, acceso a la información pública y demás procesos constitucionales, así como en casos seleccionados por la Corte para su revisión.

Estos casos representan una clara excepción al carácter de fuente interpretativa que tiene la jurisprudencia, ya que se erigen como fuentes directas en relación a interpretaciones vinculantes, así, opina Rivera (2005) que en el Estado Constitucional, en el que se ha producido la constitucionalización del ordenamiento jurídico, la jurisprudencia constitucional ocupa un lugar esencial en el sistema de fuentes del Derecho, lo que significa que la jurisprudencia constitucional es fuente directa del Derecho. (p. 349). Visto lo anterior, es evidente la evolución que ha tenido la jurisprudencia en los ordenamientos jurídicos de los sistemas continentales, el cual ya no se limita a fungir como una mera fuente de carácter interpretativa.

La Doctrina: Por último, se ubica la fuente de la doctrina, fuente que se caracteriza por ser el estudio realizado por los científicos del Derecho. Según Lastra (1994), se define como: 
La constituyen los trabajos de investigación, sistematización e interpretación que llevan a cabo los jurisconsultos en sus obras. También se da este nombre a los estudios de carácter científico que los juristas realizan acerca del derecho, ya sea con el propósito puramente teórico de sistematización de sus preceptos, ya con la finalidad de interpretar sus normas y señalar las reglas de su aplicación. (p. 42-43).

Se observa que esta fuente procura sistematizar y coadyuvar en la interpretación de las normas, siendo en ocasiones es determinante para generar futuras reformas o aspectos de lege ferenda, así como la elaboración de categorías dogmáticas que sirven de reflejo de la ciencia del derecho, al abordar los principios y fundamentos ontológicos de los diversos conceptos que hacen vida en el derecho.

\section{Fuentes del Derecho y Pluralismo Jurídico}

El pluralismo jurídico es un concepto que algunos autores remontan a la época de la decadencia romana, tal como apunta Rosillo (2017), efectivamente, fue con la decadencia del Imperio Romano en Occidente y con la implantación política de los pueblos nórdicos en Europa, que se generó la idea de que a cada individuo le sería aplicado el Derecho de su pueblo o de su comunidad local. (p. 3041)

De igual manera, se asocia su surgimiento al mundo medieval, según Grossi (2003):

Antonio Carlos Wolkmer realiza un recorrido histórico, partiendo del mundo medieval, donde la descentralización territorial y la multiplicidad de centros de poder configuraron, en cada espacio social, un amplio espectro de manifestaciones normativas concurrentes, conjunto de costumbres locales, fueros municipales, estatutos de las corporaciones por oficio, dictámenes reales, Derecho Canónico y Derecho Romano. (p. 29)

Posteriormente, la estatización del derecho fue un duro golpe para la concepción del pluralismo jurídico, al manejarse la política centralizadora y la subordinación de la ley al absolutismo monárquico. Aspecto que se mantuvo a través de los siglos XVII y XVIII, al eliminarse las estructuras medievales de las organizaciones corporativas. Igualmente, tal aspecto se fortaleció con la Revolución francesa, e incluso con las reformas napoleónicas, que codificaron la legislación civil, centralizándose el sistema jurídico.

Ahora bien, posterior a este centralismo que ha predominado en los últimos siglos, surgieron varios autores que cuestionaron la idea del centralismo, entre los que destacan Von Savigny, quien según Ceballos (2010), en su pensamiento es donde se encuentran las primeras ideas sobre el pluralismo jurídico, al indicar que:

Como es sabido, este autor se opuso a la codificación del derecho germánico a comienzos del siglo XIX, pues ello le parecía un intento de cristalizar criterios inmutables relativos a la convivencia humana, criterios que, según él, debían conservar su plasticidad y adecuación al espíritu del pueblo, histórico y por tanto siempre cambiante. (p. 228).

Así, puso de relieve su idea que el Derecho está presenten en el denominado espíritu del pueblo, que es quien realmente materializa la evolución de la cultura. Partiendo de la anterior idea, surgieron una gran variedad de autores posteriores, que enarbolaron la idea del pluralismo jurídico como realidad social, abordándolos algunos desde una óptica sociológica y antro- 
pológica (Sir Henry Maine, Émile Durkheim, Radcliffe-Brown, Pritchard, Malinowski, Eugene Elrich, George Gurvitch, Henry Lévy-Bruhl) y desde un enfoque jurídico (K. Carbonier, Santi Romano, Galanter, Boauventura Santos y Antonio Carlos Wolkmer, entre otros).

Tales autores han sido protagonistas e impulsores de la concepción pluralista del derecho que predomina actualmente, que ha permitido materializar dos instrumentos internacionales de capital relevancia, como lo son el Convenio 169 de la Organización Internacional del Trabajo "OIT" (1989), que se erige como el principal instrumento de carácter internacional que procura la tutela o protección de los derechos indígenas, y de minorías, así como la Declaración de las Naciones Unidas sobre los derechos de los pueblos indígenas (2007).

La tendencia pluralista no se queda en dichos instrumentos, sino que se abre paso en Latinoamérica, ya que precisamente en virtud del fenómeno de la colonización, resulta más común la presencia de sistemas paralelos en virtud de la imposición de nuevos sistemas monistas o unitarios y es evidente que quedan resquicios de las costumbres, practicas o usos ancestrales, resistentes a la colonización. En vista de ello, en Latinoamérica en la década de los años 90, se comenzó a incorporar o reconocer constitucionalmente la temática del pluralismo (principalmente reflejado en los Derecho de los pueblos y comunidades indígenas), tales como Ecuador (1998-2008), Colombia (1991), México (1992-2000), Bolivia (1994-2009), Guatemala (1998) y Venezuela (1999).

Tal situación, nos lleva a aducir que en la actualidad existe una fuerte presencia del pluralismo jurídico, que responde a diversas realidades y necesidades de actores sociales, tales como campesinos, indígenas, comunidad afrodescendiente, entre otros grupos. Lo cual conlleva a confirmar que instrumentos internacionales, así como constituciones y autores destacados en Latinoamérica entendiendo que el derecho normativo clásico no es la única forma de manifestación de la ciencia jurídica, sino que convergen otros aspectos de carácter social, político o económico que generan fuentes del derecho, más allá de una ley, lo cual requiere que sean tomados en consideración, este es el caso del pluralismo jurídico que no se maneja con una fuente formal directa y otras de carácter interpretativa sino que se basan principalmente en una fuente, que es la costumbre.

Lo anterior conlleva a afirmar que el pluralismo jurídico es una perspectiva que amplía las fronteras conceptuales del Derecho más allá de la concebida por la ciencia jurídica tradicional, y subraya que la manifestación de lo jurídico no se agota en el derecho estatal ni todas las culturas jurídicas existentes se reducen a la tradición jurídica occidental, siendo ésta más bien, una más de una pluralidad de expresiones existentes socialmente, aun cuando haya logrado globalizarse e imponerse sobre los demás sistemas jurídicos concurrentes, manifestada mediante la fuete de la costumbre, que viene dada o fundamentada en aspectos de diversidad cultural, interculturalidad, pluricultural y de plurinacionalidad, que forman parte de una identidad.

Así tenemos que el pluralismo se trata de un concepto que resalta la coexistencia de diversos sistemas jurídicos, en un mismo espacio, lo cual implica lógicamente, que existe un sistema Estatal, en tal sentido, no puede confundirse con los sistemas jurídicos principales o básicos, continental y anglosajón, en virtud que estos existen de manera unitaria, es decir, no coexisten, un Estado se puede manejar solo con uno de ellos. Otro aspecto es que estos sistemas puedan presentar mixturas, entre aspectos de derecho escrito y otros consuetudinarios, ello motivado a la evolución que vienen presentado algunas fuentes del derecho que han adquirido mayor protagonismo en los últimos tiempos (tales como la jurisprudencia -especialmente la vinculante u obligatoria- o la propia costumbre). 
Al respecto, apunta Salgado (2009), que:

El Ecuador como un Estado intercultural y plurinacional, su reconocimiento se encuentra establecido en la Constitución Política del Ecuador del año 2008, donde las nacionalidades y los pueblos indígenas son reconocidos sus derechos colectivos en lo que se refiere al ámbito jurídico y particularmente en el establecimiento del pluralismo jurídico, la misma que conlleva al reconocimiento de los valores, principios y normas jurídicas, y este contexto constitucional marca el inicio del nuevos estado plurinacional de nuestros derechos individuales y colectivos, de esta forma revitaliza las prácticas de usos y costumbres.

Lo anterior refleja la importancia de la costumbre como fuente principal de estos sistemas plurales. Asimismo, al revisar el concepto de concepto de justicia (o derecho) indígena, que es la principal o más rica representación del pluralismo, se maneja, según Díaz y Antúnez (2016), así:

Como aquellas prácticas resultantes de las costumbres de cada comuna, comunidad, pueblo y nacionalidad indígena, a través de las cuales las autoridades legítimamente elegidas por sus miembros regulan diversos ámbitos de las actividades, relaciones sociales y todo tipo de conflicto que se desarrolla dentro de su comunidad. (p. 6).

El anterior concepto nos conduce a hablar de varios aspectos jurídicos que circundan tal sistema, en primer término, es preciso advertir que se trata de un derecho consuetudinario, por ende está basado en la costumbre, es decir, la fuente directa aplicada (en principio, ya que por más costumbre ancestral que se trate, la misma está sujeta a límites constitucionales) es la costumbre, fuente que fue abordada al inicio de esta obra y a pesar que la costumbre, doctrinariamente exige dos aspectos básicos (exterioridad y reconocimiento) aunque no sea técnicamente una costumbre en términos exactos la doctrina clásica, indiscutiblemente es costumbre, ya que estas prácticas externas, reiteradas y reconocidas, son observadas por todos los miembros de la comunidad.

Igualmente, debe destacarse que una de las finalidades de la justicia indígena es atender a un valor comunitario, tal como apuntan Díaz y Antúnez (2016): En este contexto le corresponderá a la autoridad indígena como la encargada de cumplir y hacer cumplir las normas, los valores y principios comunitarios (...) (p. 7).

Por otra parte, debemos destacar que la costumbre va a variar conforme a cada comunidad indígena, es decir, no existe un compendio o prácticas universales que sean observadas por todas las comunidades indígenas en general, todo lo contrario, cada comunidad posee sus prácticas y estas no son recogidas por escrito, sino transmitidas de generación en generación y variopintas según el pueblo que se trate, aun cuando pueden tener aspectos en común como deidad por la naturaleza, entre otras.

\section{Lo sostenido anteriormente es ratificado por Díaz y Antúnez (2016):}

En el campo del Derecho la justicia indígena carece de un ordenamiento jurídico escrito en una ley que la tipifique y sancione, no existe un procedimiento de juzgamiento previsto en un código, norma jurídica, estatuto o reglamento; está basada únicamente en su derecho propio, consuetudinario, esto se debe a que la justicia indígena no se sustenta en un órgano especializado, ni se origina en una ley escrita, surge del seno de la comunidad indígena (...) (p. 7). 
Sostenidas las anteriores consideraciones queda claro que en materia de justicia indígena (como máxima representación del pluralismo jurídico) la fuente que se manifiesta principalmente es la costumbre, la cual permite manejar este sistema plural conforme a una fuente común, es decir, un origen del derecho, tanto material como procesal.

\section{Conclusiones}

Los Estados en su mayoría promueven el centralismo jurídico, a pesar de ello, como manifestación de las diversidad, surgen sistemas plurales que se manejan con fuentes distintas a las clásicas directas e indirectas, en el caso que nos ocupa, Ecuador se perfila como un país con un sistema de derecho continental, ya que reviste mayor importancia la ley, siendo esta la fuente de derecho material y directa, no obstante, existen otras fuentes de cardinal relevancia, fundamentado en que Ecuador es un Estado -tal como señala el artículo 1 de la Constitución- intercultural y plurinacional, lo que quiere decir que el pluralismo es plenamente reconocido constitucionalmente y por tanto deben ser consideradas todas sus vertientes al momento de legislar, por ello convergen diversos sistemas de derecho que coexisten y se manejan con distintas fuentes, plenamente reconocidas por el más alto grado del orden jurídico que es la Constitución.

Por último, vale destacar que la fuente de derecho que predomina a nivel de pluralismo jurídico, es la costumbre, en virtud de su íntima relación con la diversidad cultural que se manifiesta en la identidad de los pueblos, destacándose la cultura indígena, que es característica del país, comunidad a la que se reconocen sus derechos, prácticas, usos y saberes, reconocidos a nivel nacional ya que al tratarse de prácticas ancestrales reiteradas en el tiempo, mutan a derecho consuetudinario. En tal sentido, el sistema de justicia indígena coexiste con el sistema estatal, en un enfoque de convivialidad, en el entendido que tiene su derecho propio y por tanto, la costumbre impacta directamente en el sistema de derecho como fuente primaria para la creación de las fuentes materiales. 
Referencias bibliográficas

Ceballos, R. (2010). La idea de pluralismo jurídico. España. Departamento de Filosofía de la Universidad de Pamplona.

Código Civil del Ecuador (2005)

Constitución de la República del Ecuador (2008)

Convenio 169 de la Organización Internacional del Trabajo “OIT” (1989).

Declaración de las Naciones Unidas sobre los derechos de los pueblos indígenas (2007). Asamblea General de las Naciones Unidas, sesión 61, Nueva York, 13 de septiembre de 2007.

Díaz, E. y Antúnez, A. (2016). Derecho y Cambio Social, La Justicia Indígena y el Pluralismo Jurídico en Ecuador. El Constitucionalismo en América Latina. Ecuador. Revista Derecho y Cambio Social.

García, E. (1989). Filosofía del Derecho. México. Editorial Porrúa.

Gottheil, J. (1960). Common Law y Civil Law. Buenos Aires. Editorial Abeledo Perrot.

Grossi, P. (2003) Mitología jurídica de la Modernidad, Madrid: Trotta.

Lastra, J. (1994). Fundamentos de derecho, México, McGraw-Hill.

Legarre, S. y Rivera, J. (2006). Naturaleza y dimensiones del "Stare Decisis". Revista Chilena de Derecho. Volumen $33, N^{\circ}$. Chile.

Martínez, B. (2011). Nueva Perspectiva del Sistema de Derecho Continental en Colombia. Revista lus et Praxis. Año 17, Número 2. Colombia.

Mila, F. (2012). Manual de Introducción al Derecho. Venezuela. Editorial Vadell Hermanos.

Monroy, M. (2015) Introducción al Derecho. Colombia. Editorial Temis.

Olaso, L. (2007) Introducción al Derecho. Venezuela. Universidad Católica Andrés Bello.

Rivera, J. (2005) Fundamentos sobre el carácter vinculante de las resoluciones del Tribunal Constitucional. № 9 . Madrid. Anuario Iberoamericano de Justicia Constitucional

Rosillo, A. (2017). Pluralismo Jurídico en el constitucionalismo mexicano frente al nuevo Constitucionalismo Latinoamericano. Revista Direito Práx. Volumen 8. Brasil.

Salgado, H. (2009) La nueva dogmática constitucional en el Ecuador. México. UNAM.

Salgado, H. (2014). Introducción al Derecho. Tercera Edición. Ecuador. Corporación de Estudios y Publicaciones.

Sirvent, C. (2015). Sistemas Jurídicos Contemporáneos. México. Editorial Porrúa. 